Proceedings of the Second Annual Forestry Symposium 1996: Management and Sustainable Utilization of Forest Resources, Sri Lanka, 6-7 December 1996. (Eds. Amarasekera, HS, Ranasinghe, D M S HK and Finlayson. W). Published by Department of Forestry and Environmental Science, University of Sri Jayewardenepura, Sri Lanka (1998)

\title{
AN ECONOMIC ASSESSMENT OF THE SUSTAINABILITY OF TRADITONAL AGROFORESTRY SYSTEMS: THE CASE OF KANDYAN FOREST GARDENS
}

\author{
N.K. Batagalle', H.B. Kotagama' and D.M.A.H. Senaratne ${ }^{2}$ \\ ${ }^{1}$ Department of Agricultural Economics, University of Peradeniya; \\ - Department of Agriculture, Regional Agricultural Research and Development Centre. \\ Aralaganwila
}

\begin{abstract}
A feature of the Sri Lanka Forestry Sector Master Plan of 1995 is the promotion of conservation-oriented methods of forest management. In this context agroforestry systems such as Kandyan forest gardens (KF(is) are important, since they are not only productive and relieve pressure on the natural foresis, bitt also conserve a rich collection of biodiversity. Although national policy seeks to promote agroforestry in order to achieve nationally desirable objectives, the successful adoption of this policy depends on the degree of congruence between different national objectives, the multiple objectives of farmers, and changing socio-economic conditions. The objective of this study was to make an economic assessment of $\mathrm{KFG}$, from the point of view of the individual farmers who operate under changing and varied economic ohjectives. Data were collected by a field survey, using a structured questionnaire. Tabular analytical techniques were then used to describe important features of KFGs. The major technique used to find out how the structure of home gardens changes with changing economic objectives was linear programming analysis by the MOTAD model. The results of the study indicate that even under the condition that a farmer's main objective is to maximize the net present value (NPV), home gardens can still be an important source of timber, because of their large component of multipurpose trees, which include species such as jak and coconut. The binding constraint of the model is land; sensitivity analysis showed that with an increase in the land area of KFGs, both the number of species and the income increase.
\end{abstract}

\section{Introduction}

Kandyan forest gardens (KFGs) represent a well known agroforestry system in Sri Lanka. In Kandy District they are the major land-use, covering more than $40 \%$ of the land area (Hochegger \& Ekanayake, 1992). According to Perera \& Rajapakse (1991) they vary in size from 0.4 to 2 ha, but the pesent study included some much smaller ones. Their structural characteristics, including density and species diversity, are 
comparable to those of natural forests in similar climates (NARESA, 1991), therefore thought to be capable of providing similar environmental services.

During the past four decades, Sri Lanka has lost more than 40,000 ha of natural forests annually (FSMP, 1995). Utilizing the forest resources have been unsustainable, in both ccological and economic terms. The necessity of formulating alternative strategies to decrease the pressure on the natural forests has often been advocated, and it was one of the considerations that led to the formulation of the Forestry Sector Master Plan (FSMP) in 1995, as a long-term plan for forest resource management.

The FSMP has recognized that non-forestry systems, including KFGs, are a viable alternative strategy of forest resource management. Policy markers are placing their hopes on forest gardens and other agroforestry systems to achieve :

- Economic objectives (production of wood and other forest products, provision of viable steady income for the rural poor, and source of livelihood for the uncmployed).

- Environmental objectives (reduction of pressure on degradation of natural forests, leaving them to fulfil their environmental and ecological functions; maintenance of biodiversity; provision of sustainable alternatives for erosive land uses in critical watershed areas).

\section{The problem}

Despite the aspirations of policy makers with regard to forest gardens and other agroforestry systems, the success of these systems will depend on the specific socioeconomic conditions and farming objectives. Forest gardens evolved historically in a context different to the one in which these new policies would be applied. They evolved as a low-resource farming system suited mainly to fulfilling the subsistence requirements of an agricultural community. It is evident that their complex structure represents a multiple set of farmers' objectives, but probably a different set to what the present day policy makers hope to achieve under the FSMP.

For various reasons, therefore, the study and analysis of farmers' real objectives and their implications deserve special attention. First, the knowledge acquired should serve to reduce the conflict between private objectives and policy objectives, and therefore to facilitate the adoption of new policies. Second, policy makers should be provided with information which will be useful in designing increasingly realistic policies in the future.

\section{Ohjectives and hypotheses}

The aim of this study was to make an economic assessment of the sustainability of KFGs in a context of changing and varied economic objectives. The specific objectives of the study were:

- The identification of the objectives of home-gardening 
- The identification of changes in the structure of home gardens with changing economic objectives.

It was hypothesized that home-gardening is guided by multiple objectives, of which the economic ones are predominant, and that change of objectives leads to change in density as well as in the diversity of the plant species used.

\section{Data sources and methods}

Primary data were gathered by using a structured questionnaire. Three visits were made to the study area before this questionnaire was prepared. Four village-level administrative units - Gangoda, Gomagoda, Galpihille and Dolapihille - were selected randomly from those of Kandy District. In these villages, 60 households were selected randomly as the primary data source. Secondary data were gathered from the Forest Department, Department of Export Agriculture, and Department of Agriculture to enrich the primary data in quantification of input-output coefficients and resource constraints.

Tabular analysis was used to examine the current status of KFGs, farming objectives. and the diversity and density of plant species. Multi-objective linear programming (the MOTAD model) was used to identify the changes in diversity and density of species that were due to changes in economic objectives.

\section{Results and discussion}

The average family size was 4.71 . Out of 60 respondents 19 (32\%) had primary, and the rest had secondary education. There were only 19 full-time farmers. Home gardens were the most important component of income for $33 \%$ of households. Members of many other households had off-farm (permanent or casual) jobs, or agriculture-based income sources other than KFGs. In $74 \%$ of the households the contribution by KFGs was less than $33 \%$ of the total money income. On the other hand KFGs provided the sole moncy income for $3.3 \%$ of the surveyed sample. All the families owned their home gardens, of which $92 \%$ were inherited. The size of those sampled ranged from 0.005 to 2.5 ha, most being between 0.1 and 0.4 ha. Species number in any one KFG ranged from 17 to 46 , with an average of 37 . Annual direct money income from KFGs ranged from Rs 2750 to 144,000 per ha, with an average of Rs 7740 . These figures exclude the values of timber, consumed outputs and environmental services rendered. Coconuts, areca nuts, bananas, pepper and avocadoes account for more than $60 \%$ of the total cash income. The highest contribution is from coconuts.

From Table 1 it is evident that, as in many agricultural activities, the objectives related to income received an important place. However, not all economic objectives were related to markets and cash income. Subsistence outputs also played an important part. It seems that other non-income-related objectives, such as leisure and the creation of a comfortable home environment, are secondary to economic ones, both market and nonmarket. 
Batagalle, Kotagama and Senaratne

Table 1 : Prioritization of objectives

\begin{tabular}{lc}
\hline Objective & Percentage frequency of reporting \\
\hline Maximize income & 95 \\
Reduce income variation (risk) & 81 \\
Production of household consumables & 81 \\
Spending leisure & 10 \\
Shade and home enviromment & 5 \\
\hline
\end{tabular}

Table 2 : Species assembly in KFGs

\begin{tabular}{llll}
\hline Frequency of occurrence & Species & Life form & Uses \\
\hline$>90 \%$ & jak & tree & multi-purpose \\
$8(1)-90 \%$ & areca nut & tree & cash \\
& mango & tree & fruit \\
& avocado & tree & fruit \\
& coffee & shrub & cash \\
$70-90 \%$ & coconut & tree & multi-purpose \\
& cloves & tree & cash \\
& banana & shrub & fruit \\
& sapu & tree & timber \\
$50-70 \%$ & durian & tree & fruit \\
& pepper & climber & cash \\
& kitul & tree & multi-purpose \\
& mahogany & tree & timber \\
\hline
\end{tabular}

As proposed by the FSMP, one of the main policy objectives is the promotion of agroforestry as a non-forest timber source. When the structure of KFGs was screened, very few species were found to be grown only for their timber. Only two such species showed more than $50 \%$ frequency of occurrence (sapu and mahogany). However, the most important fact in this connection is that home gardens include an abundance of multi-purpose trees which provide very useful timbers; the best examples are jak and coconut (Table 2) - this cmphasizes a very useful fact that could be applied in other aspects of forestry. Although small farmers are reluctant to grow purely timber species as a major elcment of KFGs, this reluctance does not apply to multi-purpose trees. The obvious reason is that these species yield a variety of other economic benefits throughout their life span until they can be harvested as mature timber. The time taken to yield returns from a purely timber species is about $10-20$ years at a minimum and therefore the pay-back period for investment is long. Farmers, as rational economic agents who have a positive time preference, do not like to wait such a long time. From their point of view purely timber trees are a source of infrequent income, whereas multipurpose species are much more frequent sources.

Jak. which is the most prevalent species, has a high timber value as well as being a useful source of food. However, its use as a commercial timber species is restricted, by government regulations on harvesting and transport of timber. Therefore the use of jak 
trees for timber is often confined to domestic needs, mostly when they are over-mature and become less productive of food.

Branches of timber species are removed periodically and used mainly as fuelwood. When there is an excess of timber farmers sell it. Often the transactions are on a small scale and take place between two households to fulfil some domestic requirement of the purchaser.

The number of timber-producing species tends to decline as the area decreases, since farmers are motivated to have subsistence food crops and cash crops on the available limited space. This fact is confirmed by observations in the smaller home gardens, where the percentage share of timber (as well as that of perennial crops) gradually declines as the area decreases.

\section{Results of linear programming analysis}

Two linear programming models were used. In Model 1 the objective was to find the maximum possible income. subject to given land, labour and capital constraints. Note. however, that although farmers expressed these as the major constraints, there is no guarantee under the prevailing conditions that if adequate land, capital and labour were available to them they would divert these resources fully to developing their home gardens

Table 3 : Model 1: maximizing income

\begin{tabular}{lll}
\hline Species & Optimum activity levels & Shadow cost (RS) \\
\hline jak & 0.18 & 0 \\
areca nut & 0 & 16,400 \\
mango & 0 & 27,120 \\
avocado & 0 & 3975 \\
coffee & 0 & 54,160 \\
coconut & 0.02 & 0 \\
clove & 0 & 14,670 \\
banana & 0 & 19,540 \\
pepper & 0.13 & 0 \\
sapu & 0 & 4048 \\
mahogany & 0.05 & 0 \\
\hline
\end{tabular}

The objective function annual value is Rs $13,940 \mathrm{per}$ ha. This indicates the maximum possible profit that can be obtained from KFGs, subject to resource limits, by practising the activity levels suggested by the model. The sample estimat of the average annual income of KFGs was Rs 7740 per ha. The model therefore indicates that there is a possibility of increasing the income. Of the four species given by the activity levels, three have timber value (jak, mahogany and coconut). Sapu also was found close to an optimum activity, as it had a comparatively low shadow cost. 
In Model 2 (the MOTAD model) the objective was to find out the species combination that would give the highest possible income, with minimum income fluctuation subject to given land. labour and capital constraints.

Table 4 - Model 2 (MOTAD Model): maximizing income and minimizing risk

\begin{tabular}{lll}
\hline Species & Optimum activity levels & $\begin{array}{l}\text { Shadow } \\
\text { cost }\end{array}$ \\
\hline jak & 0.154 & 0 \\
areca nut & 0 & 312,800 \\
mango & 0 & 213,900 \\
avocado & 0 & 21.590 \\
coffee & 0 & 667,500 \\
coconut & 0.0113 & 0 \\
clove & 0 & 218,300 \\
banana & 0 & 217.200 \\
pepper & 0.214 & 0 \\
Sapu & 0 & 218,300 \\
mahogany & 0 & 1832 \\
\hline
\end{tabular}

The objective function anmual value is Rs 11,580 per ha. This is less than the value obtained under the income maximizing model, because when more than one objective is optimized there is a trade-off between them, and available resources have to be allocated to optimize the different objectives. This Model 2 value also is higher than the actual income gained from KFGs. Since the binding constraint for the MOTAD model was land, a sensitivity analysis was carried out, increasing the area. The results showed that when the limit for the land constraint was increased, both the number of crops suggested and the income were also increased.

There are a few important facts which merit attention regarding the two programming models. Both of them proposed optimum solutions which deviate greatly from the existing KFGs. The implication is that farmers' objectives are more multifaceted and complex than those entered in the models. It seems that for a better understanding of farmers' behaviour in respect of KFGs, other objectives related to the subsistence needs of the household. as well as leisure, living comfort, aesthetic benefits, etc should also be taken into account. However, despite these limitations, the solutions proposed by the two models can be taken to demonstrate farmers' wishes in relation to their main economic motives.

\section{Conclusion}

KFGs can be considered as components of an overall houschold economic strategy which comprises several other economic activities. Available household resources are allocated among these different activities to achieve maximum benefits to the household. There is a multiplicity both of objectives and of constraints. 
The results of the study suggest that even under the scenario where only economic objectives are considered, timber production can be expected to remain an important activity in home gardens. However, the fact that farmers actually grow more species than the models would recommend, and earn less than the potential income, indicates that their expectations of non-commercial benefits also deserve attention. It can be predicted that the maintenance of KFGs to achieve farmers' objectives will partially contribute to achieving the policy makers' objectives also. For instance. an increased number of species maintained by farmers to meet various domestic needs may ultimately contribute to the objective of conservation of biodiversity It is necessary to identify measures which will reconcile the objectives of individual farmers with the long-term social objectives desired by society in general. Future research should be carried out to identify agroforestry models which help to achieve this goal.

\section{References}

Hochegger, K. and Ekanayake, S P.. (1992). Kandyan forest gardens: in transition. MPTS News [Sri Lanka], 1 (3) 4-5.

Ministry of Agriculture Land and Forestry (1995). Sri Lanka Forestry Sector Master Plan.

NARESA (1991). Natural resources of Sri Lanka: conditions and trends. Natural Resources, Energy and Science Authority.

Perera. A H. and Rajapakse, R M N. (1991). A base line study of Kandyan forest gardens of Sri Lanka: structure, composition and utilisation. Forest Ecology and Management 45, 269-280. 